\title{
SELECTION OF EFFECTIVE SOFTWARE FOR THE ANALYSIS OF THE FRACTIONAL COMPOSITION OF THE CHAOTIC SEED LAYER USING THE EXAMPLE OF OILSEED RADISH
}

\author{
Yaroslav Tsytsiura ${ }^{1^{*}}$
}

${ }^{1 *}$ Corresponding author. Vinnytsia National Agrarian University/21008, Solnechnaya street, build 3/ Vinnytsia, Ukraine. E-mail: yaroslavtsytsyura@ukr.net | ORCID ID: https://orcid.org/0000-0002-9167-833X

\section{KEYWORDS}

fractional composition, image analysis, oilseed radish, scanning, seeds.

\begin{abstract}
This article generalises the peculiarities and efficiency of the use of three software packages, Digimizer image analysis software (v. 4.2), ImageJ2 version 2.0.0-rc-64 and WipFrag 3.3.14.0. These packages were used in studying the fractional composition of oilseed radish seeds for scanning in the mode of single-layer inseparable placement. The generalisation of the main caveats and features of the effective use of each of the software packages is made on the basis of detailed analysis of the features of each of package in the use to the features of the scan and the obtained scanned image The above-mentioned aspects are illustrated in detail and reservations about the options for the effective use of each package are represented. The efficiency and expediency of using the program, ImageJ2 version 2.0.0-rc-64, with a level of identity to the standard method of determination of $75.9 \%$ and the program, WipFrag 3.3.14.0, with a similar efficiency index at $89.3 \%$ for laboratory determination of seed fractional composition were also established.
\end{abstract}

\section{INTRODUCTION}

Modern approaches to seed production technologies involve the transition from general concepts of the quality categories of seeds to the study of complex patterns of their formation. Besides, in seed production, seed size and uniformity of any crop are always considered as factors of the formation in the remote technological period, as a guarantee of high levels of field germination, crop uniformity and providing opportunities for maximum realisation of the genetic potential of the crops Silva et al., 2020). It is clear that different variants of seed are used to ensure the appropriate level of fractional composition in the practice of preparing seeds for sowing (Trujillo et al., 2019). On the other hand, it should be understood, and many researchers note that the level of variation of seed material in size, weight characteristics, organoleptic characteristics (colour, surface character, etc.) is high (Marchi \& Gomes-junior, 2017; Orandi et al., 2018; Brunes et al., 2019; ElMasry et al., 2019; Hu \& Zhang, 2020; Pinheiro et al., 2020). The size of this variability depends on such technological factors as seed formation conditions in the interaction with the level of soil and additional mineral nutrition, the intensity of the seed filling process and hydrothermal conditions during filling (Abud et al., 2018; Araújo et al., 2020). The inequality of seeds by the morphological and weight parameters significantly increases the risk of losses during mechanised harvesting and further operations of primary cleaning and stationary mechanised separation (Shevchenko \& Aliev, 2018).

The problem of determining the morphological variability of seeds for many crops is an urgent scientific task (Alomía et al., 2016; Silva et al., 2019; Zhu et al., 2020; Wu et al., 2020). In particular, it is reported that the rate of variation of individual linear seed sizes and their individual weight is quite high for cruciferous crops. Furthermore, in the process of growing this group of crops in adverse conditions, especially during seed formation and filling - it exceeds the coefficient of variation of its value by $20 \%$ (Shevchenko \& Aliev, 2018). The oilseed radish is also no exception, maintaining this figure at $12-$ $32 \%$ and having a complex nature of formation of morphotypes of the seed itself in comparison with other representatives of the family (Tsytsiura, 2019). Thus, studying the possibility of using appropriate software packages to allow determination of the effectiveness of the methodology and its practical value was selected. It is also necessary to stipulate the modern approaches to determining the individual morphology of seeds using the 
methods of processing scanned images of seeds. The process scheme consists of obtaining images of the seed mixture on a contrasting background surface and its further processing by different algorithms among existing methodologies (Alomía et al., 2016; Belin et al., 2018; Gong et al., 2018; Silva et al., 2019, 2020; Hu \& Zhang, 2020). The algorithms can be conditionally divided into three main groups. The first group involves the use of appropriate software based on Visual Studio C ++ (Python, Java) and the OpenCV library ( $\mathrm{Li} \& \mathrm{He}$, 2017; The OpenCV Reference Manual, 2019; Wu et al., 2020) which can analyse all images obtained from a camera or by scanning. As a result of the analysis, the seeds are automatically identified by taking consecutive points around their perimeters and maximising or minimising the values in the following sequence: image loading; conversion to a 1-bit image (black seed on a white background); morphology analysis to remove noise and gaps; contouring by marking all the seeds in the image and calculating the length $\mathrm{L}$, width $\mathrm{B}$, area $\mathrm{S}$ and length of the perimeter P of the seed (Dong et al., 2019; Zhu et al., 2020). In this method, it is possible to place the seeds with a uniform distribution over the scan area and the ability to more clearly separate along the contours of its location The use of this method with the chaotic mixing of single-layer seed thickness consists of the formation of appropriate image preparation, its chromatic transformation and corresponding binarisation (Zilbergleit \& Temruk, 2017; Wu et al., 2020).

The second methodological algorithm involves scanning images of seeds on a contrasting background, scaling the image using a standard ruler, binarisation of the image relative to the main background of seed placement and determining such individual morphological parameters of seeds as length, width, circumference, perimeter and area due to the calculation of the binary image The placement of seeds evenly on the scanned surface with no contact with each other is an important requirement for the effective use of this method (Yan et al., 2011). This group of methods in scientific practice involves the use of the ImageJ software package with an appropriate methodology for determining the size of pre-processed images (Jayapriya \& Hemalatha, 2019). It is also possible to use other program versions to process scanned images. For instance, the software packages Digimizer, GrainScan, SmartGrain, SeedCount and others (Tanabata et al., 2012; Liu et al., 2017; Belin et al., 2018; Wu et al., 2018; Silva et al., 2019; Medeiros et al., 2020; Wu et al., 2020; Zhu et al., 2020) can be used.

The third type of methodology involves scanning the placed total layer of seeds with further analysis of their size using programs to analyse the fractionality of the image (Dilip \& Sahu, 2017; Unajan et al., 2019; Bai et al., 2020).

In the format of the third methodology, there is currently no effective software for seed scanning. This is caused by the above-mentioned features of the image processing, which intensively contact with the surface and form common objects in the process of binarisation and segmentation, which belong to one fractional element. At the same time, the appropriate command options for eroding, contour fragmentation, etc. are used to differentiate such elements (Rueden et al., 2017). For these reasons, we researched the possibility of using the WipFrag program, which is mainly used to determine the fragmentary composition of rock structures in geology, mineral processing technology, construction, etc. (Sereshki et al., 2016). The hypothesis of the study foresees the possibility of the effective use of the WipFrag 3.3.14.0 package for the accelerated methodology to determine the fractional size of seeds in the general fragment of their single-layer chaotic arrangement (fused seed mass).

\section{MATERIAL AND METHODS}

This research was conducted at Vinnytsia National Agrarian University ( $\left.49^{\circ} 11^{\prime} \mathrm{N}, 28^{\circ} 22^{\prime} \mathrm{E}\right)$. Oilseed radish with high fractional variability of seeds was used as a test culture. The 'Zhuravka' variety was used in the research. The seeds were grown in 2019. Seeds for the study underwent two levels of purification without calibration to obtain a heterogeneous mass. A CanonScan LiDE $700 \mathrm{~F}$ scanner with a resolution of $600 \mathrm{dpi}$ was used for scanning. Before scanning, the seeds were placed in one layer on a transparent film with a dimensional side ruler. The results of processing the scanned images included 20 seed variants. Each variant of the obtained scanned image was processed sequentially by three computer programs such as Digimizer image analysis software (v. 4.2) (MedCalc Software Ltd, Belgium), ImageJ bundled with java 1.8.0_1722 software package (open source) and WipFrag 3.3.14.0 software package (University of Waterloo, Ontario, Canada). These programs are widely used in scientific practice for automated manual determination of morphological parameters of various scanned images of objects. Processing of scanned images was performed in full accordance with the relevant manual for each program (Maerz \& Palangio, 1999; Whan et al., 2014; Broeke et al., 2015; Rueden et al., 2017; Hu et al., 2019; Shehu et al., 2020).

The obtained results of scanned image processing in different software packages were compared with the standard Ukrainian method of determining the fractional composition of seeds (SSU 4138-2002, 2003). The weight of seed fractions was determined by scales RADWAG PS 1000.R1 with the discreteness of $0.001 \mathrm{~g}$, The final results of processing the scanned image processing were imported for statistical processing into the software packages Statistica 10 and Excel 2013.

\section{RESULTS AND DISCUSSION}

The use of the Digimizer image analysis software (v. 4.2) has some technical limitations in processing a scanned image of the inseparable seed layer massif. The scanned image processing system, even in case of image sharpness correction systems using the automatic system of sharpness correction, lighting and formation of appropriate variants of colour, black-and-white image of scanning during binarisation, which necessarily precede the format of morphometric analysis of the scanned object (the morphometric indicators that can be determined; they are as follows: length, width, area, perimeter, radius, corner characteristics, circumference, coordinate characteristics, etc.) allows an image massif most suitable for analysing the seed massif using the classic multichannel colour (red, blue, green) way to binarise the image (Figure 1). 


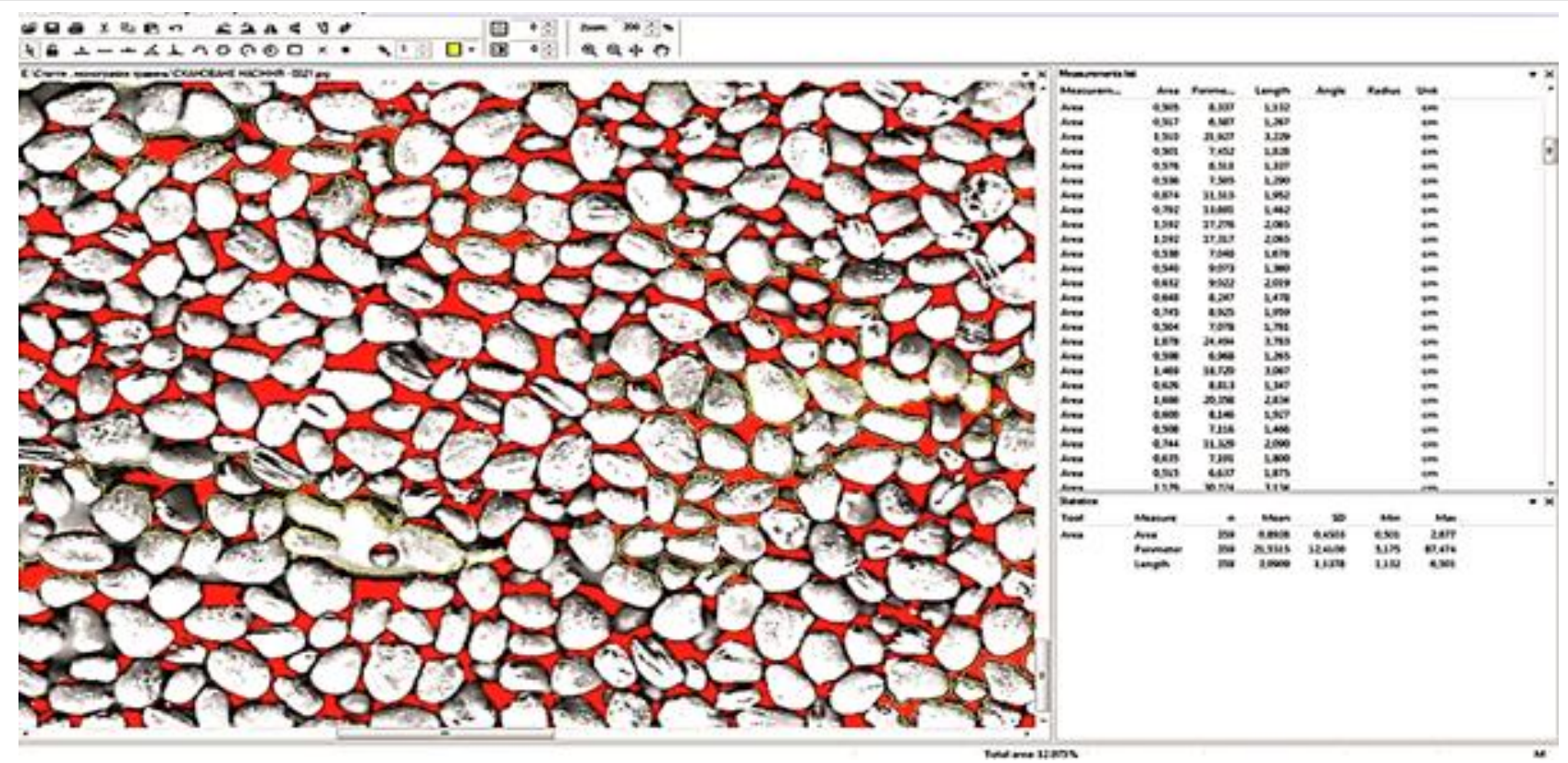

FIGURE 1. One of the variants of the selected format of the binary image of the array of oilseed radish seeds in manual mode processing in the working window of the Digimizer program (v. 4.2).

But in the process of determining the size of the some seeds by the pre-scaling we obtain two types of indicators that included the inter-seed space, which is included in the specified interval of the morphological dimension, and the scanned seed massif program perceives it as a whole, forming it as one indicator or several parts according to the boundaries of the most pronounced interspecific intervals. As a result, we obtained the massif of data which could be used only after appropriate manual correction and only for the relatively comparable analysis of the seed size (Figure 2).

Taking into account the assertion about the need to use tools which allow to define the boundaries of the objects by the analogy with the OpenCV FindContour function in case of the presence of such important options as Erode and Dilate in the analysis of the images with different morphological structure (Ansari et al., 2017; Dilip \& Sahu, 2017; Rajani \& Veena, 2019; Unajan et al., 2019; Zhu et al., 2020).

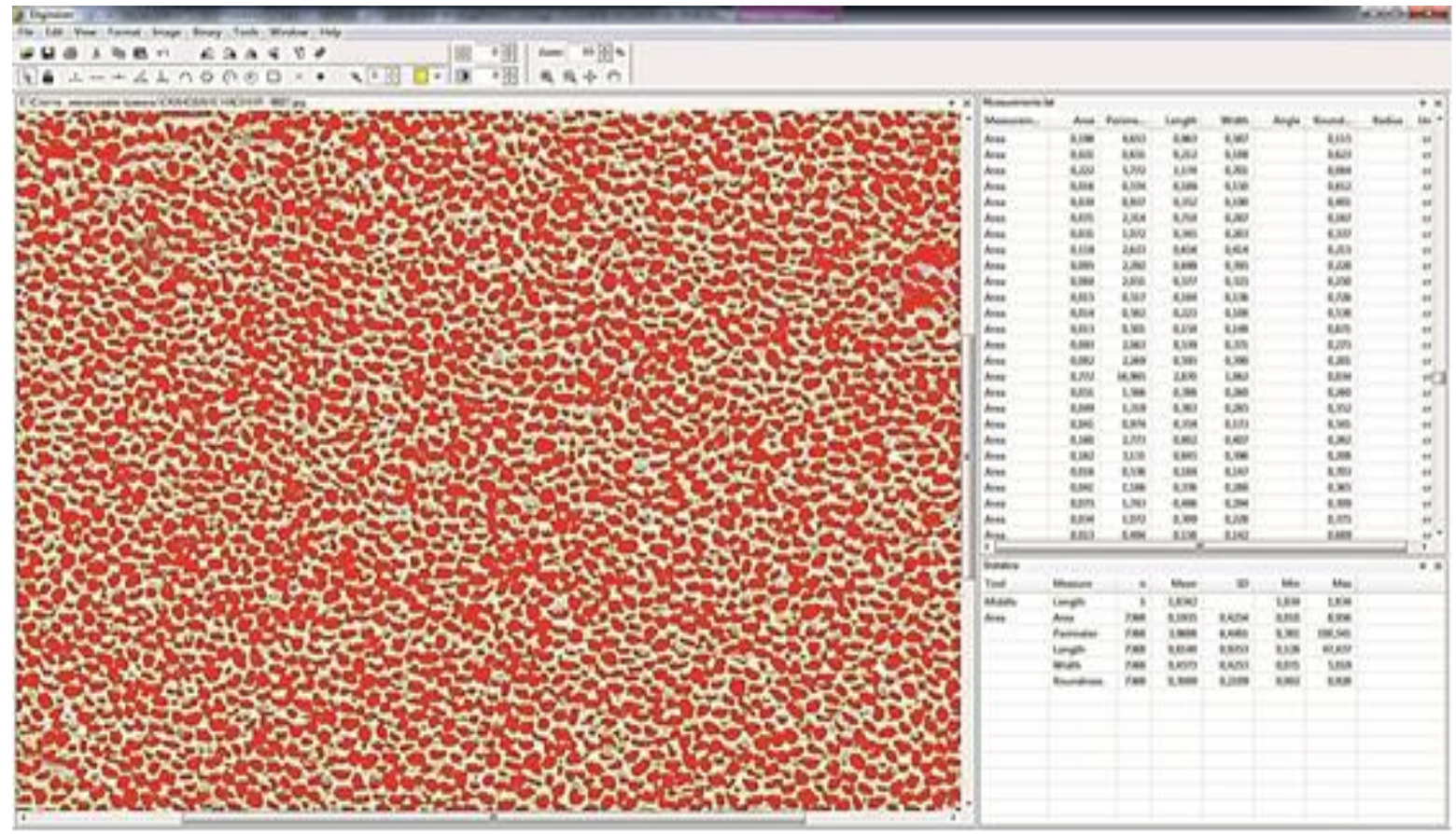

FIGURE 2. Seed array format after the standard procedure of analysis of morphoparameters of the scanned image in the working window of the Digimizer program (v. 4.2). 
The software package, Digimizer v. 4.2, should be recommended as an important tool for determining the seed morphological parameters in the use of scanned image processing at the interval remote seed placement because, as we shall show later, the program package, WipFrag 3.3.14.0, does not allow image defragmentation with the intervals between the fragments which form the single scanned image system due to the specifics of the scanned image processing (Maerz \& Palangio 1999; Tosun, 2018).

The efficiency of using Digimizer when scanning with a uniform distribution of seeds on the scanned surface is also determined by the nature of such uniformity because, even in case of the explicitly the seeds placed separately during the binarisation and pre-processing of the scanned image have the nature of the connected element and are analysed as a single structure (Figure 3 ).

The effectiveness of Digimizer v. 4.2 in this scanning option is confirmed in our studies. Thus, due to this program for 3 hours of the operations mainly on the uniform distribution of seeds on the scanning surface the main morphological parameters of more than 3.5 thousand seeds were determined. In particular for such parameter as its fragmentary size is shown in Figure 4.

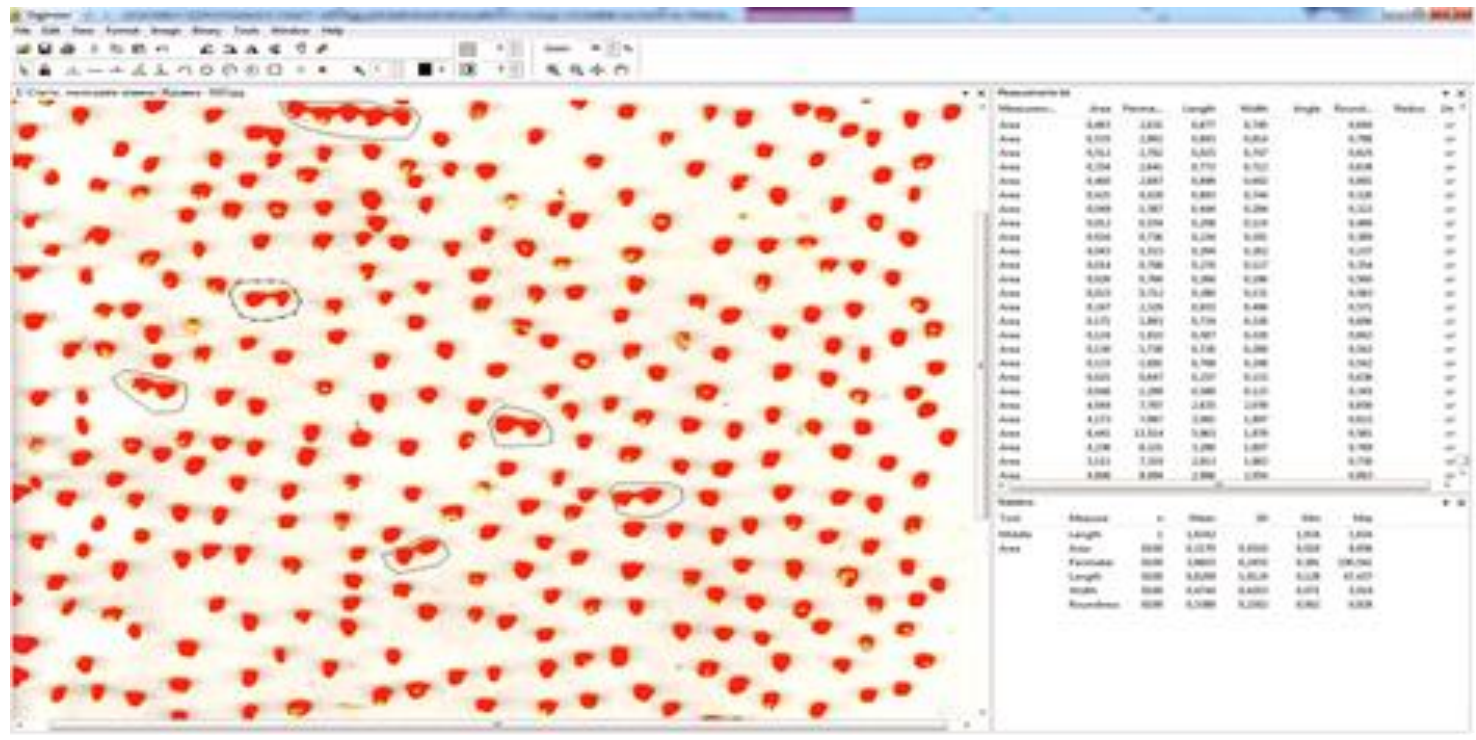

FIGURE 3. The nature of processing the scanned image of the seed at its uniform-interval distribution after preliminary preparation for morphological processing of the binary image in the working window of Digimizer v. 4.2 (connected seeds during image processing are marked with circular concentric structures).

Similar studies regarding ImageJ2 version 2.0.0-rc64 confirmed the program's advanced capabilities for scanning image processing options, including the abovementioned image border determination operators, reducing the thickness of the selected borders and options to increase delimitation between individual seeds in the massif (Aliev et al., 2017; Belin et al., 2018; Mittal et al., 2019; Wu et al., 2020).

The informative sequence of using this program including the function 'Find Edges' is shown in Figure 5. As a result, after the calibration of the dimension of the image and the option of analysis of its fractional parts, we can obtain data concerning of seed morphological parameters.

The statistical letter of the measurements of the program differs from the similar letter for the Digimizer program and provides reception of such indicators as the area of the scanned image of the seed surface, perimeter and form description. This limits the informativeness of the data on the individual morphological characteristics of the seeds but such functions as detail characterisation, determination of centring, asymmetry, etc. are added.

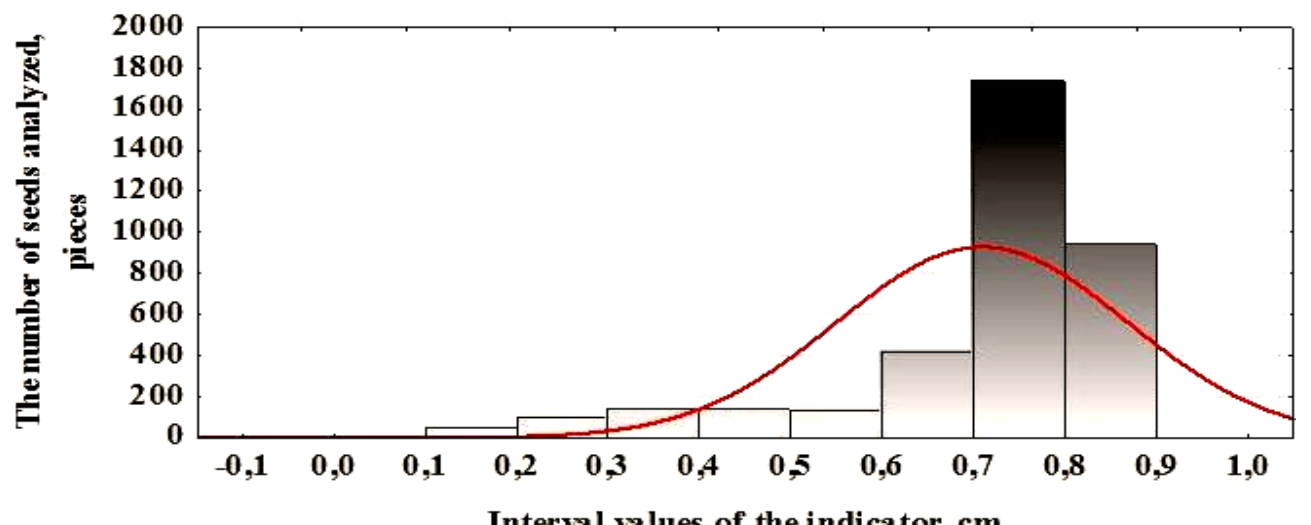

FIGURE 4. Interval distribution of oilseed radish in terms of total fractional size (roundness) based on the results of the individual interval image of scanned seeds in the environment of the Digimizer program (v. 4.2) for one of the experimental scanning options, 2019. 

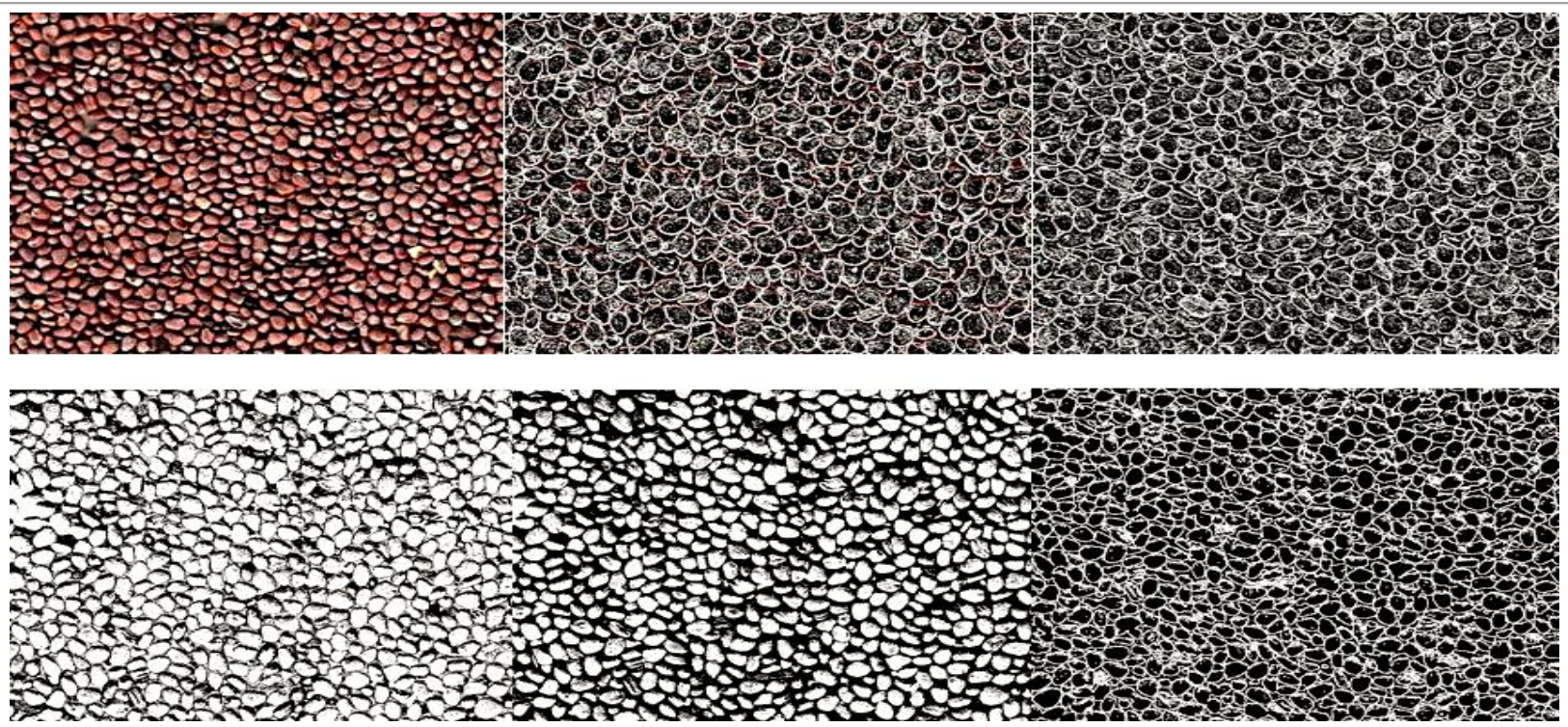

FIGURE 5. Sequence of processing the scanned image of seeds in the ImageJ package bundled with the java 1.8.0_172 program (sequentially left-right and top-down: gradual transition from the colour scanned image in 32-bit to the monochrome image in 8-bit with inclusion of the function 'Find Edges' and subsequent image processing in the 'Threshold' and 'Binary' options in B\&W mode), 2019.

The question of the quality and tonality of the binarisation of the image and the clarity of the boundaries of the individual seeds remains problematic. Due to the shades of colour which are most pronounced in the boundary zones at the contact boundary of the seeds, the shade of the binarisation threshold is more intensive than in the centre of each separated boundary fraction of the seed. As a result, the nature of the analysed surface, which is formed in the transformed seed scan, has a complex nature with intensive gradations of reflection (Figure 6).

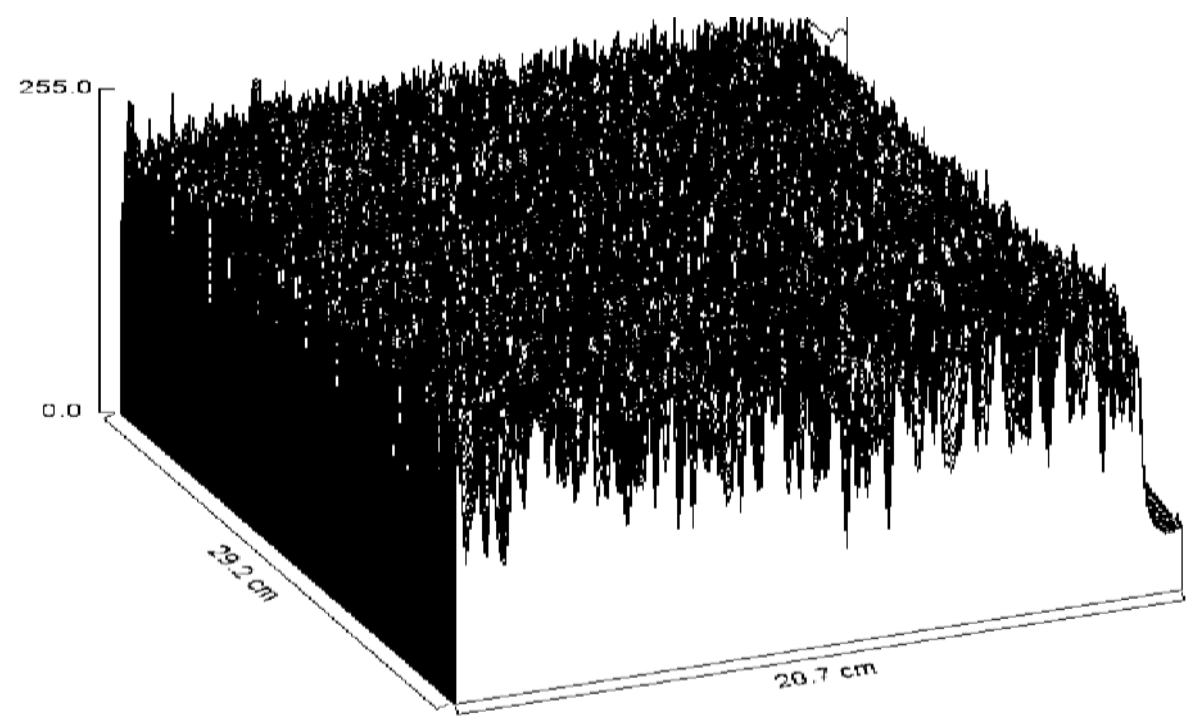

FIGURE 6. The nature of the surface of the 8-bit converted scanned image of oilseed radish seeds after threshold binarisation operations in B\&W mode, 2019.

The represented display threshold's depth, with a maximum of 255 units, is significantly different and it ultimately affects the analysis of the morphology of the individual boundary fractions of the image and can lead to errors in the final size of each seed, even in cases of correct and accurate scaling to ensure pixel conversion to real metric dimensions ( $\mathrm{cm}$ and $\mathrm{mm}$ ). However, similar conclusions regarding the general scanning of various objects were represented in a number of other studies (Broeke et al., 2015; Alomía et al., 2016; Zilbergleit \& Temruk, 2017; Mariscal et al., 2019; Zhu et al., 2020; Hu $\&$ Zhang, 2020). The possibility of using this program for individual determination of individual morphological parameters of seeds at their interval distribution on the scanned surface has also been researched (Figure 7). 

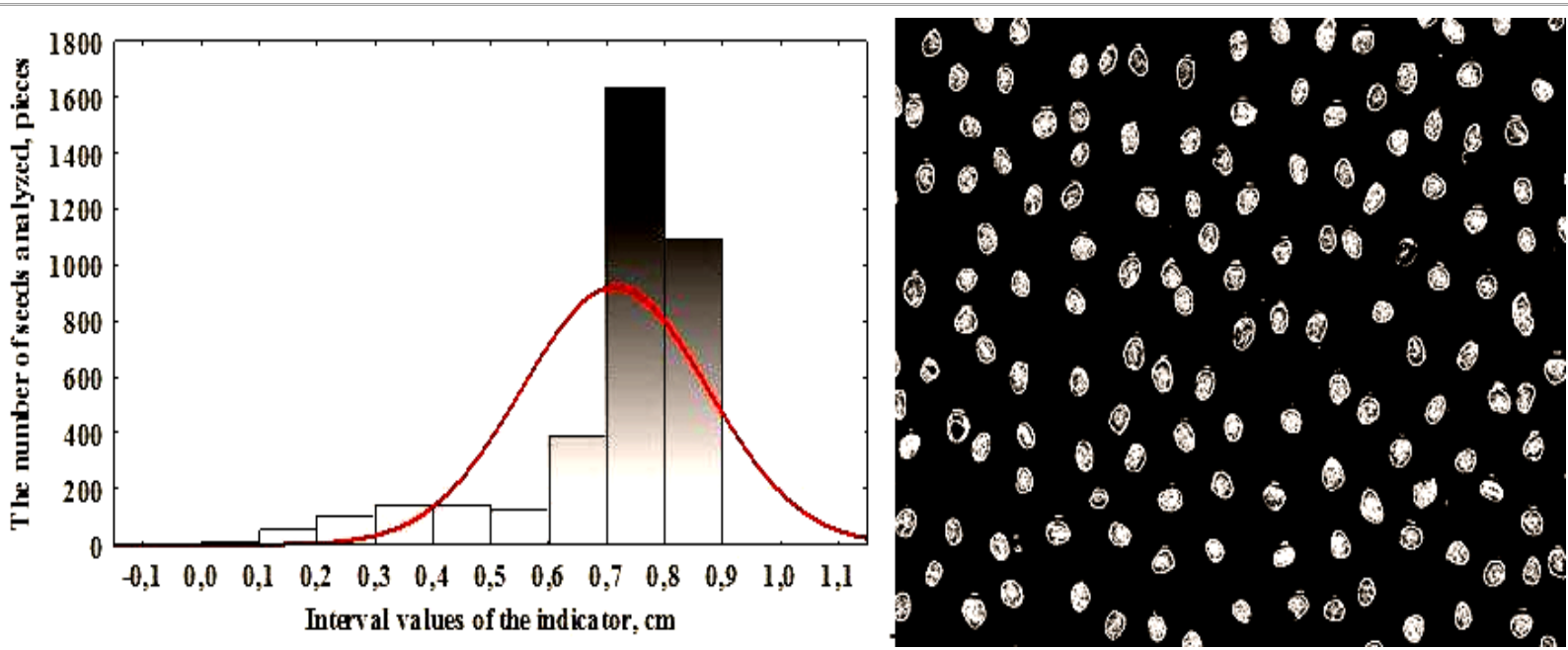

FIGURE 7. Interval distribution of oilseed radish by total fractional size (roundness) based on the results of the individual interval image of scanned seeds in the environment of the ImageJ program bundled with java 1.8.0_172 and prepared for calculation of scanned image morphological parameters (sequential transition from colour scanned 32-bit image to 8-bit monochrome image with 'Find Edges' enabled and subsequent image processing in 'Threshold' and 'Binary' in B\&W mode), for one of the experimental scan options, 2019.

The data displayed in one of the similar indicators represented for the Digimizer program in Figure 4 demonstrate the similarity of the obtained individual morphological data of seeds. However, according to our estimates, due to the larger tools for processing the scanned image, the interval range of this indicator was larger for the ImageJ program. On the other hand, the interface for displaying data with the results of their output in 'xls' format for the Digimizer software package was more understandable and convenient in terms of their statistical representation.

Regarding WipFrag 3.3.14.0, we should note that this program was used for the first time in our research to determine the fractional composition of seeds, because as mentioned above, it is programmed for use for other research purposes. Its main feature includes a fairly simple and clear interface, the ability to load pre-processed images in various programs, including the abovementioned Digimizer and ImageJ (Figure 8).
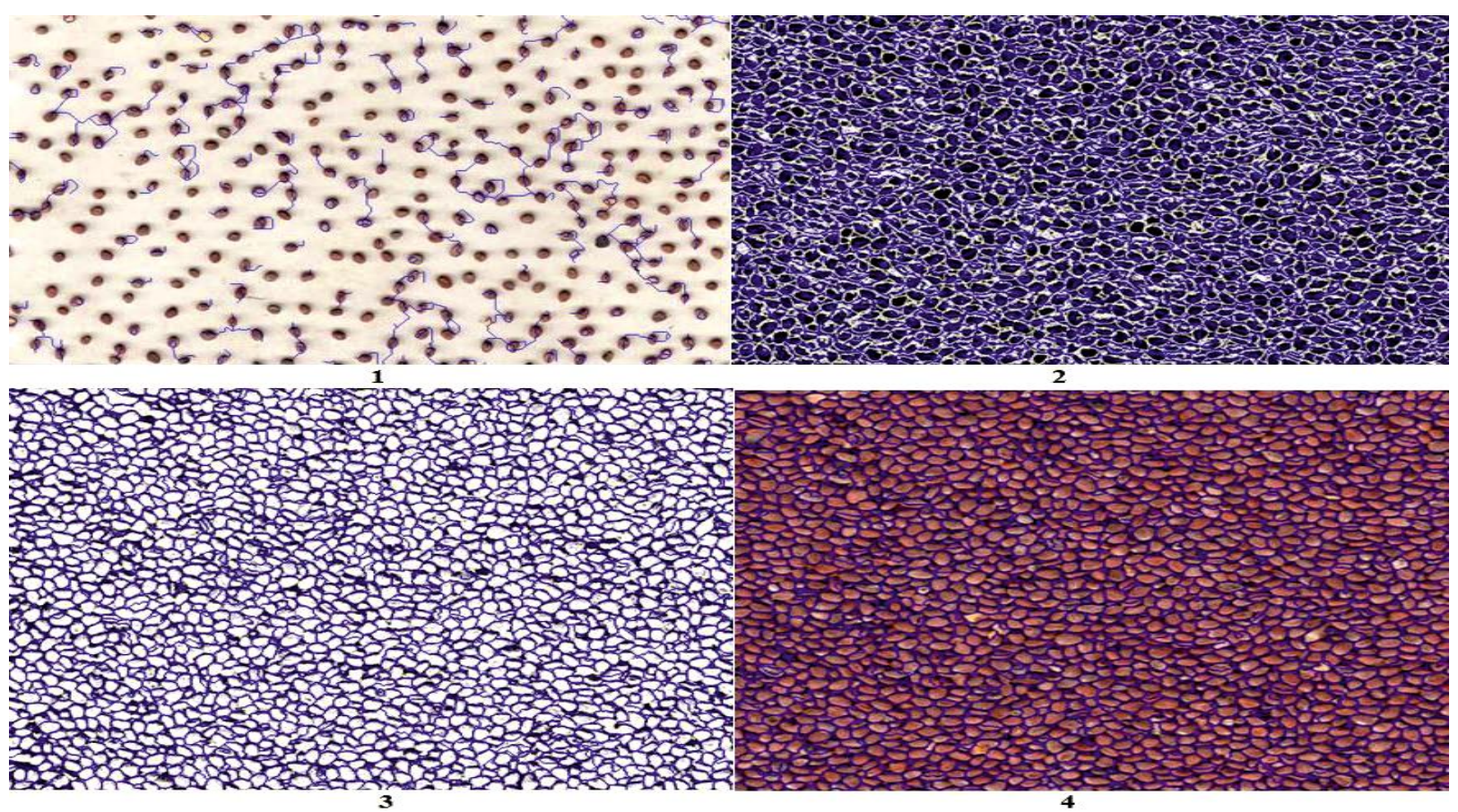

FIGURE 8. Different options for processing scanned seed images in the software system WipFrag 3.3.14.0: 1 - option for the individual interval placement of seeds; 2,3 - seed image prepared in advance in the ImageJ program (different intensity of threshold binarisation in B\&W mode); 4 - full colour original scanned image of the seed layer, 2019.

It should be noted that the use of the program is possible only in the case of scanning the general surface layer of seeds, as the program does not form a skeletalfractional structure of the image in the format of the individual interval placement. Therefore, further morphological analysis is impossible. In the process of our research, we tested different formats of analysis of the scanned images with different binarisation. It is 
necessary to note that the most complete skeletonisation, which copies the fractional size of the seed layer, is marked during the analysis of the full profile colour scan in case of its formation by the layer of the clearly limited correct edges on the perimeter of the scanned mass. This reduces the number of problem areas of the correct orientation of the grid fractional skeletal image shown in
Figure 9. The problem areas are marked in the figure with blue circles and arise due to differences in the altitude of the nearby seeds. As a result, the gradient of the vertical effect arises and affects the skeletalisation of the image observed in the studies of Maerz \& .Palangio, 1999), Sereshki et al. (2016), Tosun (2018), Mittal et al. (2019), Frei \& Kruis (2020).

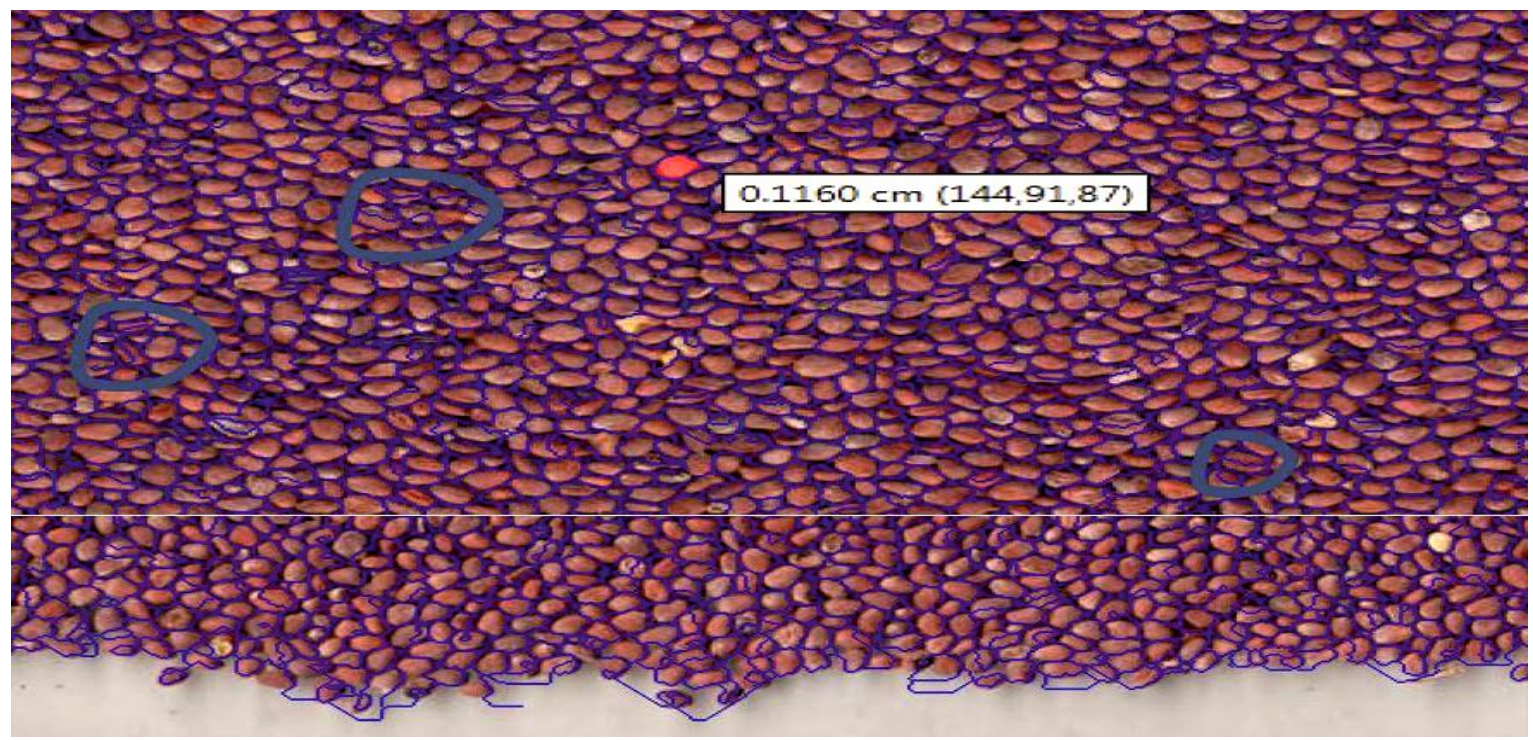

FIGURE 9. Skeletalisation of a scanned full colour image of a layer of oilseed radish seeds with the possibility of indication (example is given in the form of a colour fraction with a context menu of its size) of any seed in the overall image due to the context menu of a computer mouse. Lower position: the nature of the fragmentation of the scanned image in the marginal areas of scanning with uneven seed placement, 2019.

As a result of the automated processing of the scanned image, we obtained the measurements in the format of a diagram of the distribution of seed fractions by size (Figure 10).

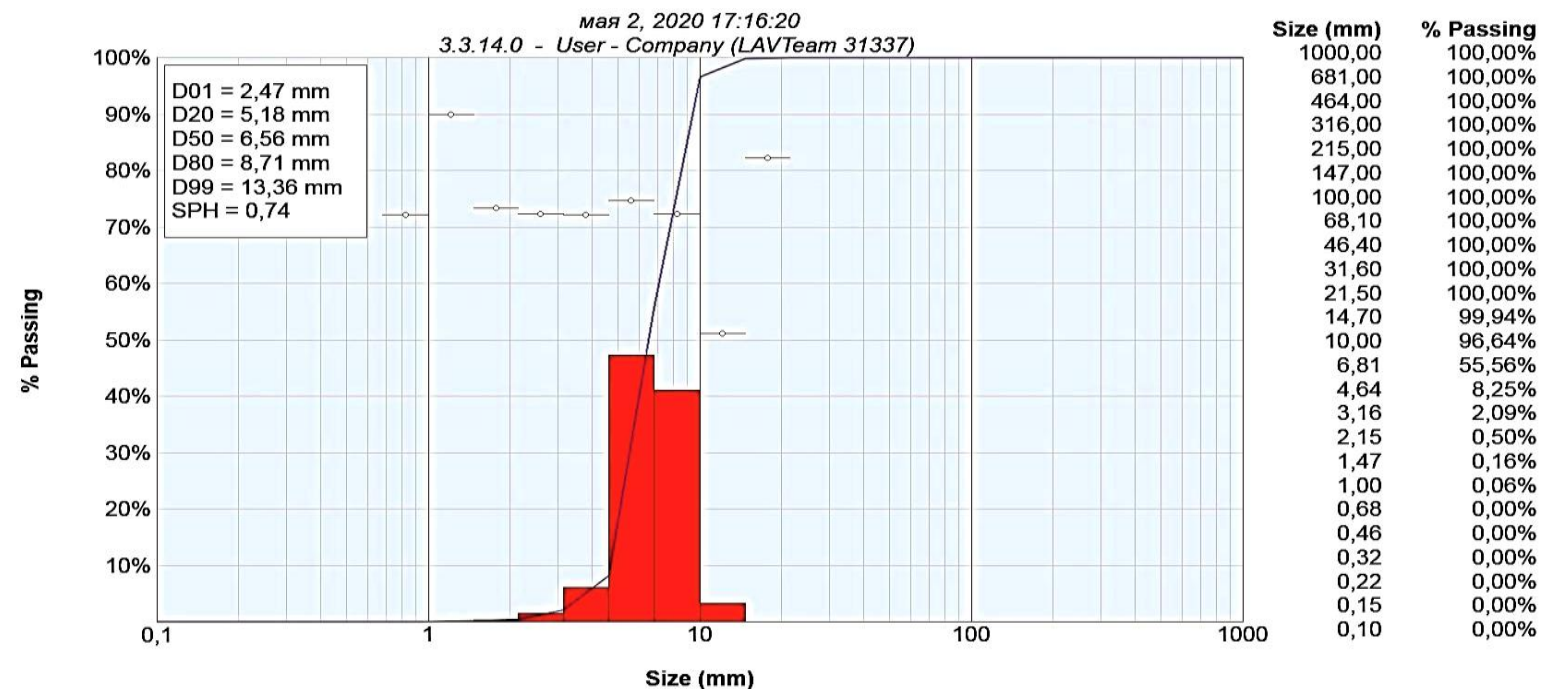

FIGURE 10. Final results of determining the size fractions of seeds in their total mass in the environment of the WipFrag 3.3.14.0 program for one of the experimental scanning options, 2019.

In the comparison of the consistent diagrams (Figures $4,7,10$ ), the similarity of the obtained results of the fractional size of the seeds obtained by the image processing by different program methods should be noted.
However, the real advantage of one of them can be researched by comparing the results of the used programs with the results of the standard method of sieving the appropriate number of studied oilseed radish seeds through sieves with round holes (SSU 4138-2002, 2003) (Table 1). 
TABLE 1. The results of determining the fractional composition of oilseed radish seeds (\%) by different methods, 2019 (averaged for 20 scan samples).

\begin{tabular}{|c|c|c|c|c|}
\hline \multirow{2}{*}{$\begin{array}{l}\text { Dimensional fractions of } \\
\text { seeds, } \mathrm{mm}\end{array}$} & \multicolumn{3}{|c|}{$\begin{array}{l}\text { Use of processing of the scanned image of seeds in } \\
\text { the program }\end{array}$} & \multirow{2}{*}{$\begin{array}{c}\text { Standard method of determination } \\
\text { (sieving through sieves with round holes) } \\
\text { (SSU 4138-2002, 2003) }\end{array}$} \\
\hline & $\begin{array}{l}\text { Digimizer } \\
\text { (v. 4.2) }\end{array}$ & $\begin{array}{l}\text { Image J2 version } \\
2.0 .0-\mathrm{rc}-64\end{array}$ & $\begin{array}{l}{ }^{* * *} \text { WipFrag } \\
3.3 .14 .0\end{array}$ & \\
\hline & \multicolumn{4}{|c|}{ fractional composition of oilseed radish seeds $(\%)$} \\
\hline $0.5^{*}(\text { до } 3.0)^{* *}$ & 3.40 & 3.93 & 0.92 & 1.14 \\
\hline $1.0(>3.0)$ & 9.42 & 12.22 & 3.83 & 7.47 \\
\hline $1.5(5$ and $>)$ & 4.45 & 4.24 & 4.63 & 9.53 \\
\hline $2.0(6$ and $>)$ & 57.07 & 50.68 & 46.23 & 42.47 \\
\hline $2.5(8$ and $>)$ & 25.65 & 28.93 & 41.02 & 38.52 \\
\hline $3.0(10$ and $>)$ & 0.00 & 0.00 & 3.31 & 0.87 \\
\hline $3.5(11$ and $>)$ & 0.00 & 0.00 & 0.06 & 0.00 \\
\hline
\end{tabular}

* - the diameter of the holes of the sieves according to the State Standard of Ukraine (SSU) 4138-2002 (2003); ** - the size fraction of oilseed radish seeds corresponding to the diameter of the sieve holes in terms of the length of the circle $\pi \mathrm{D} ;{ }^{* * *}-$ fractions adapted according to the method of interpretation of the fractional composition of seeds by Maerz \& Palangio1999).

According to the represented results, the programs used provide quite credible values regarding the nature of the fractional composition of seeds according to the features of the surface scanning in comparison with the standard method of determination. Taking into account that both the Digimizer v. 4.2 program and the ImageJ program are currently widely used with java 1.8.0_172 in the case of determining the morphological parameters of plant parts including seeds (Broeke et al., 2015), according to our estimates, WipFrag 3.3.14.0 software can also be successfully used for the express evaluation of the fractional size of the seed massif. The comparative analysis showed a number of remarks regarding the use of these program products. Some were noted in the process of analysing the effectiveness of the use of the program operators. In particular, the Digimizer v. 4.2 program showed the lowest accuracy of determinations in comparison with the other programs due to certain features of the need for certain conditions of seed separation during scanning and due to the lack of a number of important blocks for the preparation of the scanned image for analysis. However, we should note its comfortable interface for the output results of the measuring.

ImageJ2 version 2.0.0-rc-64 confirmed its effectiveness in the processing and analysis of the scanned images. However, its problem area consists of the work in preparation of the scanned images, in particular for the multicolour nature of the scanned surface, which is characteristic of oilseed radish seeds. For these reasons in case of the increasing the threshold image processing the lighting zones appear due to which the object is calculated with a smaller actual parametric dimensions.

It is confirmed by the obtained highest values of the small fractions in our research. On the contrary, small fractions of seeds often fall into the format of deformed skeletalisation for the WipFrag 3.3.14.0 software package due to the same features of skeletalisation (fragmentation). We noted this in Figure 9. This causes an artificial increase of the fractional size when getting into the higher fractional gradation. We should also note that the program worked well with the large fractions of oilseed radish seeds and showed the highest approximation to the size fraction of the sieves of 2.0 and $2.5 \mathrm{~mm}$, according to the standard method of determination.

\section{CONCLUSIONS}

Thus, our research gives grounds to confirm the effectiveness of determining the fractional composition of seeds in the general seed mass placed with a uniform thickness on the scanned surface using two software products: the well-known ImageJ program and WipFrag 3.3.14.0, a new program for this field of activity. In comparison with the standard method of determining the fractional composition of oilseed radish seeds, the first program provided a total percentage of identity at the level of $75.9 \%$ and the other program at the level of $89.3 \%$. This allows us to recommend them for use in the system of laboratory determination of the linear and fractionalweight characteristics of seeds of different crops, considering the reservations and assessments made by us in the process of the research and represented in this article. The results obtained in this research are important for the sowing sector, which seeks to automate the analysis of seeds, increasing speed and accuracy in the results.

\section{REFERENCES}

Abud HF, Cicero SM, Gomes-junior FG (2018)

Radiographic images and relationship of the internal morphology and physiological potential of broccoli seeds. Acta Scientiarum: Agronomy 40(1): 1-9.

Aliev E, Pryshliak V, Yaropud V (2017) Research of physical and mechanical properties of oilseed crops, MOTROL. Commission of Motorization and Energetics in Agriculture 19(3): 103-108.

Alomía YA, Muñoz E, Acosta-Range AM, Tupac Otero J (2016) Morphometric analysis of vanilla seeds (orchidaceae) by microscopic techniques. Lankesteriana 16(1): 21-26.

Ansari MA, Kurchaniya D, Dixit M (2017) A comprehensive analysis of image edge detection techniques. International Journal of Multimedia and Ubiquitous Engineering 12(11): 1-12. 
Araújo JO, Dias DCFS, Medeiros AD, Silva LJ,

Nascimento WM (2020) Chickpea seed vigor evaluated by computerized seedling analysis. Semina: Ciências Agrárias (42)1: 71-86.

Bai X, Zhang C, Xiao Q, He Y, Bao Y (2020) Application of near-infrared hyperspectral imaging to identify a variety of silage maize seeds and common maize seeds. The Royal Society of Chemistry 10:11707.

Belin E, Douarre CM, Gillard N, Franconi F, Rojas-Varela J, Chapeau-Blondeau FO, Demilly D, Adrien J, Maire E, Rousseau D (2018) Evaluation of 3D/2D imaging and image processing techniques for the monitoring of seed imbibition. Journal of Imaging 4:83.

Broeke J, Perez JMM, Pascau J (2015) Image Processing with ImageJ. Packt Publishing, 2 ed. 256p.

Brunes AP, Araújo AS, Dias LW, Antoniolli J, Gadotti GI, Villela FA (2019) Rice seeds vigor through image processing of seedlings. Ciência Rural 49(8): 1-6.

Dilip BD, Sahu DK (2017) A brief review of image segmentation based on thresholding technique. IJRASET 5(3): 293296.

Dong W, Ma X, Li H, Tan S, Guo L (2019) Detection of performance of hybrid rice pot-tray sowing utilizing machine vision and machine learning approach. Sensors 19:5332.

ElMasry G, Mandour N, Al-Rejaie S, Belin E, Rousseau D (2019) Recent applications of multispectral imaging in seed phenotyping and quality monitoring - An overview. Sensors 9(5): 1090.

Frei M, Kruis FE (2020) Image-based size analysis of agglomerated and partially sintered particles via convolutional neural networks. Powder Technology 360: 324-336.

Gong L, Lin K., Wang T, Liu C-L, Yuan Z, Zhang D-B, Hong J (2018) Image-based on-panicle rice [Oryza sativa L.] grain counting with a prior edge wavelet correction model. Agronomy 8:91.

Hu R, Li F, Yu H, Yang J (2019) Use of ImageJ in the rock thin section image analysis: the separation and quantitative calculation of crystal-glass two phases. SDRP Journal of Earth Sciences \& Environmental Studies 4(3): 609-616.

Hu Y, Zhang Z (2020) GridFree: a python package of image analysis for interactive grain counting and measuring. bioRxiv - Bioinformatics. DOI: http://dx.doi.org/10.1101/2020.07.31.231662

Jayapriya P, Hemalatha DrS (2019) Comparative analysis of image segmentation techniques and its algorithm. International Journal of Scientific \& Technology Research 8(10): 2209-2212.

Li B, He C (2017) Segmentation algorithm of touching rice kernels based on skeleton features of image background. Journal of Computational and Applied Mathematics 37: 198-202.
Liu T, Chen W, Wang Y, Wu W, Sun C, Ding J, Guo W (2017) Rice and wheat grain counting method and software development based on Android system. Computers and Electronics in Agriculture 141:302-309.

Maerz NH, Palangio TC (1999) WipFrag. System II Online fragmentation analysis. FRAGBLAST 6, Sixth International Symposium for Rock Fragmentation by Blasting. Johannesburg, p111-113.

Marchi JL, Gomes-junior FG (2017) Use of image analysis techniques to determine the embryo size of Senna multijuga (Rich.) seeds and its relation to germination and vigor. Journal of Seed Science 39(1):13-19.

Mariscal EG, Haro CG, Donati L, Unser M, MuñozBarrutia A, Sage D (2019) Deepimagej: a user-friendly plugin to run deep learning models in ImageJ. BioRxiv: 799270 .

Medeiros AD, Silva LJ, Silva JM, Dias DCFS, Pereira MD (2020) IJCropSeed: an open-access tool for highthroughput analysis of crop seed radiographs. Computers and Electronics in Agriculture 175:105555.

Mittal M, Verma A, Kaur I, Kaur B, Sharma M, Goyal LM, Roy S, Tai-hoon K (2019) An efficient edge detection approach to provide better edge connectivity for image analysis. IEEE Access 7:33240-33255.

Orandi G, Calvini R, Foca G, Ulrici A (2018) Automated quantification of defective maize kernels by means of multivariate image analysis. Food Control 85:259-68.

Pinheiro DT, Capobiango NP, Medeiros AD, Caiafa KF, Dias DCFS, Pinheiro AL (2020) Assessment of the physical and physiological quality of Piptadenia gonoacantha (Mart.) J.F. Macbr seeds using image analysis. Revista Árvore 44:4426.

Rajani S, Veena MN (2019) Medicinal plants segmentation using thresholding and edge based techniques. International Journal of Innovative Technology and Exploring Engineering 8(6S4):71-76.

Rueden CT, Schindelin J, Hiner M C, DeZonia BE, Walter AE, Arena ET, Eliceiri WK (2017) ImageJ2: ImageJ for the next generation of scientific image data. BMC Bioinformatics 18:529.

Sereshki F, Hoseini S M., Atae M (2016) Blast fragmentation analysis using image processing. International Journal of Mining and Geo-Engineering 50(2): 211-218.

Shehu SA, Yusuf KO, Hashim MHM (2020) Comparative study of WipFrag image analysis and Kuz-Ram empirical model in granite aggregate quarry and their use for blast fragmentation rating. Geomechanics and Geoengineering 1-9 (Published online: 06 Feb 2020

https://www.researchgate.net/publication/339090128) DOI: https://doi.org/10.1080/17486025.2020.1720830.

Shevchenko IA, Aliev EB (2018) Research on the photoelectronic separator seed supply block for oil crops. INMATEH - CUPRINS 54(1): 129-138.

Silva LJ, Medeiros AD, Oliveira AMS (2019) SeedCalc, a new automated $\mathrm{R}$ software tool for germination and seedling length data processing. Journal of Seed Science 41(2): 250-257. 
Silva JA, Medeiros AD, Pereira MD, Ramos AKF, Laércio Junio da Silva J (2020) Seed quality analysis of Senna siamea Lam. using image analysis techniques. Journal of Seed Science 42:e202042042.

State Standard of Ukraine (SSU) 4138-2002 (2003) Seeds of agricultural plants. Methods of quality determination. Valid since 2004.01.01. Kyiv: Derzhspozhyvstandart Ukrayiny, 173p. (in Ukrainian).

Tanabata T, Shibaya T, Hori K, Ebana K, Yano M (2012) SmartGrain: high-throughput phenotyping software for measuring seed shape through image analysis. Plant Physiology 160: 1871-1880.

The OpenCV Reference Manual. Release 2.4.13.7. (2019) Available: https://docs.opencv.org/2.4/opencv2refman.pdf. Accessed July 10, 2020.

Tosun A (2018) A modified Wipfrag program for determining muckpile fragmentation. Journal of the Southern African Institute of Mining and Metallurgy 18: 1113-1119.

Trujillo HA, Gomes-Junior FG, Cicero SM (2019) Digital images of seedling for evaluating coffee seed vigor. Journal of Seed Science 41(1): 60-68.

Tsytsiura YH (2019) Evaluation of the efficiency of oil radish agrofitocenosis construction by the factor of reproductive effort. Bulgarian Journal of Agricultural Science 25(6): 1161-1174.
Unajan MC, Gerardo BD, Medina RP (2019) A modified otsubased image segmentation algorithm (OBISA).

Lecture Notes in Engineering and Computer Science. In: International MultiConference of Engineers and Computer Scientists. Hong Kong, Proceedings... p363-366.

Whan AP, Smith AB, Cavanagh CR (2014) GrainScan: a low cost, fast method for grain size and colour measurements. Plant Methods 10(1): 231.

Wu WH, Zhou L, Chen J, Qiu Z, He Y (2018) GainTKW: a measurement system of thousand kernel weight based on the android platform. Agronomy 8: 178.

Wu D, Cai Z, Han J, Qin H (2020) Automatic kernel counting on maize ear using RGB images. Plant Methods 16: 79 .

Yan L, Park CW, Lee SR, Lee CY (2011) New separation algorithm for touching grain kernels based on contour segments and ellipse fitting. Journal of Zhejiang University-SCIENCE 12: 54-61.

Zhu F, Paul P, Hussain W, Wallman K, Dhatt BK, Irvin L, Morota G, Yu H, Walia H (2020) SeedExtractor: an opensource GUI for seed image analysis. bioRxiv. DOI: http://dx.doi.org/10.1101/2020.06.28.176230

Zilbergleit MA, Temruk VI (2017) The use of IMAGEJ package for processing images obtained by electron scanning microscopy (for example, paper analysis). Polymer Materials and Technologies 3(1): 71-74. 